\title{
Team Management: A Reflection on Leadership to Achieve Success
}

\author{
Dionise Magna Juchem, Edgardo Alfredo Herrera Céspedes \\ Federal Institute Farroupilha, Santa Rosa, Brazil \\ Fábio Augusto Marin \\ Federal Institute of Rio Grande do Sul, Bento Gonçalves, Brazil \\ Michelle Nazaré Cunha \\ UNINTER, Belém, Brazil
}

\begin{abstract}
This study aims at rethinking the posture and attitude of professionals in managerial and leadership positions, regarding the organizational management, showing that it is possible to motivate a team, valuing the human and maintaining a good working environment, with respect and collective participation towards a common good by focusing on problem solving regardless the resources that the company can offer to encourage and satisfy its employees. In order to prepare this study, survey was conducted from empirical studies, literature surveys, and qualitative and quantitative approaches were used in a company linked to the tobacco sector. The results show that companies are still adapting to new paradigms of the market and seek to achieve greater productivity with the accomplishment of teamwork, considering aspects such as leadership, motivation, and interpersonal relationships.
\end{abstract}

Keywords: management, leadership, motivation, management teams

\section{Introduction}

Since the industrial revolution the behavior of society and the labor market have undergone changes and adaptations. Companies, in turn, focus on the role of people within organizations, expanding their competitive vision, and the most striking feature of this process is the humanization of company staff.

Thus, the incentives offered by the company are not the only motivational stimulus, since the leadership exercised by the person in charge of management and employee satisfaction is primarily responsible for achieving and exceeding business goals. But for this to happen it is necessary to make the employee feel valued and inserted in such process.

Such thing does not always occur due to the way the employee is viewed and treated by his superior in the company. If the priority is only the achievement of goals they can be kept under strict supervision and always

Dionise Magna Juchem, Ph.D. in Management and Direction of Companies, Department of Business and Management, Federal Institute Farroupilha.

Edgardo Alfredo Herrera Céspedes, MBA in Engineering and Materials Technology, Department of Mechanical, Federal Institute Farroupilha.

Fábio Augusto Marin, MBA in Management and Organization, Department of Management and Organization, Federal Institute of Rio Grande do Sul.

Michelle Nazaré Cunha, MBA in Management, Department of Business and Management, UNINTER.

Correspondence concerning this article should be addressed to Rua Uruguai, 1675, Bairro Central, CEP 98900-000, Santa Rosa, Rio Grande do Sul, Brazil. E-mail: dionisejuchem@gmail.com. 
need the supervisor to monitor the fulfillment of their basic tasks, which wears out both parties, keeping a vicious cycle of dissatisfaction and demotivation where the professional waits for the first opportunity to move to another company.

\section{Workforce}

Usually called workforce or team, however, a common misconception occurs, since there are differing definitions of the concepts of group, team, and teamwork.

Reis (2007) considered that groups and teams differ by the interdependence of the member and the relation with organizations. In groups, task performance depends essentially on the individual responsible for it, and besides, the tendency is for the organization to determine the objectives to be met and the procedures to be followed, and yet on teams, although there is task distribution, each individual must take responsibility before a portion of the whole, the responsibility for the results and for achieving the goals is for all components, noting also that when, for any reason, a member is unable to act, another takes position.

In addition, teams within organizations tend to take consideration on the definition of the purpose and procedures to be adopted for its implementation, resulting in a greater commitment of members. Thus, according to Reis et al. (2007), all teams are groups; however, not all groups are teams.

The team management is taken by matters of objective order (explanation) as productivity and achievement of goals, and is permeated by subjectivity (understanding) of the relationships and interpersonal conflicts, changes, doubts, fears, and feelings that make humans relate (Kaspary \& Seminotti, 2012).

França (2011) addresses the same way, a differentiation between the team and team work, in relation with the group and the organization, but observing the bases of Reis (2007), are paralleling only on terminology. Thus, corresponding to the group and staff and staff to team, França (2011) defined a workforce as a group of people involved in the development of a task or job, for which the members possess some involvement and commitment to the philosophy and outcome of the task developed. Being those individuals involved with the development of certain tasks, but led by an officer who receives and transmits information of process steps, which all together accomplish the task.

Team work is what presents the differential and is based on a set of individuals who seek a common action associated with a particular purpose. Members of a team are aware of all information, steps, and philosophy of work to be done. Individuals are led by a responsible group that seeks to integrate the tasks to be undertaken, seeking to motivate, engage, and involve the sense of responsibility of each individual and emotional work.

In this case, this differentiation occurs, much more, by applying the term to the reality within institutions, than the theoretical sense that has been updated on terminology, but it follows the same line of thought. Process that can result from overuse of a current term in reference to another distinct meaning, then there is a distortion of empirical knowledge, and with it, changing the direction of the object discussed.

\section{Team Work}

Team work is, without a doubt, one of the main determining factors of success, and even the failure of organizations, which remains as a great difficulty. In other words, it is the critical factor in organizational success as a whole and its maintenance in particular. The team should be trained and developed, the tasks should be well designed to be carried out successfully, and one of the most important roles is that of manager who should lead and motivate with the purpose to achieve certain goals (Chiavenato, 2009). 
It is observed that there are still companies that fail to form a real team for their maintenance and operation, searching for solutions and success for the organization.

Kardec (2002) stated that it is common to find experts pointing out the error of each other over which he has no action, forgetting his own problem that he can and should act upon. There must be functioning organizational processes that benefit the formation of mixed teams conducting coordinated and integrated activities, in order to achieve more productive goals for organizations.

According to Peters (1989), the success of teamwork depends, among others, on their goals to be cleared and defined, of its multifunctional and simultaneous implication, on full time, and avoids shared resources, but also involves people outside the staff, and especially of a clear and precise communication.

Another claim from Reis (2007) and Lacombe and Albuquerque (2008) are that the greatest opportunity for participation and involvement of staff with objective and with the processes, tasks, and responsibilities, tends to bring the individual to personal accomplishment.

Organizational structures based on teams provide advantages over traditional hierarchical structures, as Wagner III and Hollenbeck (2003) and Sacomano Neto and Escrivão Filho (2000) said. They emphasize that teamwork enables organizations to be faster and more efficient in the preparation and finalization of products and services to be put on the market, and warn that these types of structure based on teams suppress the need for a large number of varying levels of middle management.

Thus favoring greater autonomy to employees in the performance and completion of tasks, decisions that were ahead of managerial authority, providing greater satisfaction to the members of the team achieving a better performance in all activities and behavior required according to the position they hold in organizations.

Among other advantages of teamwork, we can mention that the agility in capitation and use of the information, and how they are based on different points of view, the production of ideas is of higher quality, more elaborate and richer, which arise from multidisciplinary group, and further, since the result is the responsibility shared by the group, there is a greater tendency to take risks, as there is a greater degree of commitment between the participants in order that the power is shared and people are engaged in the process with greater abetment and motivation.

\section{Leadership}

Bennis (1996) compared the leadership to beauty: It is difficult to define but easy to recognize. Because it is not simply the ability to influence individuals and groups. The concept of leadership is intrinsically linked to the stimulation and motivation. It goes further, pointing to a subjective approach, regarding the behavior, and the human being is not limited to magic and definite formulas bearing in mind that it encompasses many variables. Vergara (2006) warned that it refers to a more individual argument, those that concern our recesses, our guts, what moves us and what makes sense to us, to what we ascribe meaning.

To lead is to use the symbolic influence, not coercive, to direct and coordinate the activities of members of an organized group to achieve common goals of the team claim (Wagner III \& Hollenbeck, 2003, p. 244; Silva, Junquilho, \& Carrieri, 2008; Arnold, Barling, \& Kelloway, 2001). It is more than that, its human nature to know, understand, and guide people. That is, the direct process of managing people and it is through it that these organizations are able to manage the execution of tasks, allocation of financial and material resources, production of goods and services, and above all the fulfillment of their goals, their success and survival in the organizational market. It is essential in many forms of human organization. 
According to Chiavenato (2010, p. 147), leadership is constituted as an "interpersonal influence exercised in a given situation and directed through the process of human communication, to achieve one or more specific objectives". However, the lead only happens with the willingness of people to accept this influx toward the goals already predetermined by the leader.

There is a direct correlation between the ways people see their managers and the ways they are led. In all cases of effective leaders they are virtually admired by the people they lead.

Wagner III and Hollenbeck (2003) and Barling and Kelloway (2001) referred that the influence of the leader must be approved by the followers and the fact that they voluntarily surrender control of their behavior to the other person, fully pays any significance leadership.

Among the theories on leadership are: Theory of personality traits, that according to personality traits (physical intellectual, social, and the ones related to task) is crucial for the formation of the leader, that is, it is deduced by reasoning that the individual is born leader.

A theory of leadership styles, in which refers to three types of leadership: Autocratic, where the power of decision is absolute to the leader, he has specific guidelines for execution of tasks; the democratic emphasizes participation, the leader encourages and assists the group to discuss and decide on the best way to be followed; and the laissez-faire or liberal, which emphasizes total freedom in decision-making group and individual.

Contingency theory converges attention to the phenomenon of leadership, as a whole, given that it is responsible in a process of relationship between leader, regarding the influence, by nature, related to the leading position, or the issue of formal authority and personality, followers, regarding to the relationship between leaders and subordinates, interpersonal relationships, expectations, interests and motivations; and situation, with regard to the degree of structuring of the task, that understands the organization as a scenario where it is unfold the process where the task is executed, relates (Vergara, 2006).

As for Chiavenato (2010), the leadership model to be used by the leader will depend on the situation, the people and the work to be performed, as there is a unique model and superior leadership that has been used for any situation.

Leadership is the key factor for the performance of any staff with managerial excellence and business. The teams, in general, are complex because they are human and social organizations, where it is necessary to know how to guide, motivate, lead, and manage the individual differences of its members, i.e., the success of such initiatives depends on the satisfaction that depends on the leadership, which depends on the vision, dedication, competence, and primacy of their leader.

\section{Leadership and the Workforce}

The team's mission, without the use of leadership, is hardly achieved, given that organizations are driven by cooperation and unfavorable conflicts, being necessary to raise the level of cooperation and guide the disagreements to get favorable change in processes and creativity.

I am pleased to participate in regattas in Marblehead Harbor. When I am in the water, I realize that everybody compete with the same kind of boat, with the same number of crew, under the same weather conditions. However, a crew always manages to overcome others and achieve victory. Why? Because their commander knows that the ability to lead and encourage a team makes a major difference in regattas and the same happens in management. (Stevens, 2001, p. 3)

An ineffective leadership can generate many conflicts, such as dissatisfaction, loss of productivity, loss of qualified employees or lead to apathy, professional stagnation and they will stay in the same company or 
business only because of achieved results, disregarding the process for achieving such results.

When organizations provide satisfactory conditions to "empower and direct the predispositions of people and turn them into positive and practical results" (Chiavenato, 2009, p. 120), the application of human energies can be infinitely increased by creating a niche convenient for the progress and fertilization of individual skills for the benefit of the same.

According to Chiavenato (2009), the manager should encourage his team firstly by offering a communication system suitable for the participants and disburse support the harmony and performance, and second to provide training and development of their staff, as well as improve their efficiency and effectiveness in order to perform their activities in the shortest possible time.

A first step towards a good management is the relationship of the manager with his team, relationship of team members to each other as the integration and communication are organizational elements necessary for achieving positive results.

Some of the key factors determining for the efficient performance of the workforce have been linked to factors related to the task, others are related to the level of its individual components. The next aspect considered is the dyad, and still higher degree of analysis of the characteristics of the team as a whole. This analysis studies the team as a separate entity, so it is imperative for the study of the task, which must examine the individual contributions and the positive interaction between team members (Wagner III \& Hollenbeck, 2003).

Therefore, according to the vision of Wagner III and Hollenbeck (2003) and Tanure, Evans, and Cancado (2010), the level of staff commitment prevails team goals (subordination of individual interests), common goals and identities, high levels of effort and confidence. At dyadic levels of mental models are shared, i.e., members of the dyad must understand each other's respective roles. At the individual level the expertise and performance of roles are dominant, whereas the task level is the provision of critical resources and the opportunity to apply the skills.

Chiavenato (2009) believed that motivation can be intrinsic and extrinsic, and it is suppressed in people and has the possibility to be vastly influenced. The motivation process should initially be implemented in the individual and in the collective later, resulting in the enhancement of leadership and the inversion of the organizational pyramid.

Castro (1996) addressed that, for issues related to the motivation of groups in the workplace, you should first make use of self-motivation techniques, in order to subsequently strive to motivate the group as a whole.

Vergara (2006) argued that there is no magic formula to motivate someone, because this is a state that is born absolutely intrinsic to our inner needs, therefore, what can be done is to stimulate, encourage, and provoke this motivation.

According to D'Auria (2007), it is necessary to know how to motivate people to get their emotional commitment and achieve goals, valuing the professional and showing confidence in his abilities, believing that if you are a motivated professional you will be able to achieve any goal.

According to Dejours (1996), organizations are place conducive to suffering, boredom, despair, existential discomfort. Following the same reasoning, Tracey and Hinkin (1998) argued that most people end up losing interest in their job. You need to find meaning at work and reconciling personal interests with organizational goals. This meaning, depending on the needs of each individual, can be found in the economic and financial factors, or simply by the desire to be recognized, to feel competent or to participate in decisions, among others. 
"We should be constantly asking ourselves: What are the needs of the people I lead?" asked by Hunter (2007, p. 54). Under this view, it is considered as important as the salary or even more than it, good interpersonal relationships within the company and the possibility of growth, since these last two points are not related to rationality but the sensations, and emotions. Topic that has been widely discussed and related to the satisfaction and motivation, must be taken into consideration because these three factors together would meet human needs, that are: food, water, and shelter (primary), safety and security (secondary), belonging and love, self-esteem and self-realization (Hunter, 2007, p. 55).

The primary needs are physiological (to be able to feed and provide sustenance for the family as a result of work) and the need for security (also related to salary and job stability), and secondary, which are social-affective, esteem, self-realization (participation or social acceptance, being loved, related to interpersonal relationships, the prestige and respect related to the possibility of growth and also to salary and stability, to be seen by society as a worker, someone whose fixed income gives you the opportunity to take credit and with that status, related to materialism, symbolized by what individual can own or buy with their purchasing power).

Self-realization can be influenced by motivational factors provided by the company, through incentives that value their employees, but this is not decisive, since the motivation is of particular individual and therefore self-realization depends not only on external influences.

Accordingly, the personal satisfaction and professional staff are directly related to how the process takes place, how the manager leads the team, trying to motivate them to produce more and better.

Mapping relationships between these needs and benefits that the company can provide to its employees, such as salary, good relationship, growth opportunities and autonomy or interdependence to perform their work, there is a win-win relationship, considering that the employees enjoy their valuation which gives them advantages in the field and the emotional and material organizations enjoy the results from this investment through a direct investment to increase production, attracting and retaining qualified professionals, and indirect investment in endomarketing. What also helps to leave the company brand stronger with customers, market, and society?

However, on the manager position, adapting to organizational standards and serve the interests of the company and employees are complex and sometimes diverging. Because of this paradox, the behavior to lead a team cannot always be considered, by any party, fair or not free of personality characteristics, which is perfectly natural, since there is no native managers.

This knowledge is achieved with experience, supported by strong traits of character and personality. However, Reis (2007) and Stettner (2006) claimed that there are routine procedures that are within the competence of the manager and enable their work and encourage their staff, such as delegating, evaluating the performance of your team, give feedback, organize regular meetings to discuss the progress of current procedures and measures to be taken for future procedures, provide conditions for carrying out the work and motivate your team. The act of delegating is as a way of reducing their administrative tasks and thus better supervise the work of a team, in addition to improving their staff with more complex activities.

According to Stettner (2006), successful managers need to have faith in their staff. Delegate is a task that needs to be well calculated. To find the right motivation for the right professional, one must take into account the interests, strengths, and knowledge of each, and pass the task to those who have a good performance in at least two of these requirements.

However, it is necessary to be aware that delegating tasks should, therefore, be supervised, but not with 
hype, because there is the risk of hampering the independence and creativity of charge. "Strange as it may seem, the great leaders gain more authority when they give it up" (Stettner, 2006, p. 15).

To give constructive feedback, with well-deserved praise, neutral observations or a more serious warning, encourages employees to self-assessment in an effort that they have the initiative to improve. Stettner (2006) believed that constructive feedback is part of the manager's job, and that kind of feedback requires explanations to employees about the high standards of development, which produces more results than just asking the employee to change the attitude on the wrong procedure.

To provide the necessary conditions to work together is vital to the success of the team goals and the organization (Oliveira \& Limongi-França, 2005). A consideration of some factors such as the definition of enough members to allow the tasks without compromising the involvement and communication, maintaining the required dependency for carrying out the tasks as well as their distribution, in addition to maintaining good interaction between the members respecting the positions of each individual.

A good manager is not just to achieve the production expected of leadership, since there is no criteria for it, especially considering that some of the great achievements of humankind have been achieved through slavery, injustice, and intolerance, since the construction of the Egyptian pyramids, the invasions and conquests of the Roman Empire, the colonization of the Americas and Africa, the inhuman treatment of the employee resulting in the industrial revolution, among others, and even (still) the existence of slavery today in many regions and countries.

\section{Methodology}

It is necessary to understand the various ways to build the knowledge; it should be the focus of all experiences to be grounded by the theory and constantly related to the practice, in search of a critical-reflective view both on knowing and doing.

Scientific methodology should not be seen primarily as means of spreading knowledge of methods and techniques for planning, conducting, and presenting scientific research, but as a branch of knowledge that elucidates what comes to these techniques and methods which serve science, and epistemological bases that are justified.

The development of this study took place gradually from the empirical research and based on studies and literature and quantitative-qualitative approach in a distributor of smoke originating products.

With the objective of outlining the approach, it was applied a research on satisfaction and motivation in such distributor, we'll call it Company A, which coordinates its activities in the retail and wholesale sector, and operates in the northern region of Brazil and has three branches distributed in that region. The study was implemented in the flagship store, with 15 employees.

In the survey, questions about the knowledge of the company work philosophy were addressed: the existence of a department of personnel management and the quality of their performance, the organization of the labor sector, the evaluation of performance on the tasks performed; professional growth and opportunities offered by the organization, the stimulus and encouragement of teamwork, ease of communication, training and development, motivation, feedback, recognition, commitment and also leadership (Juchem \& Cespedes, 2012).

The questionnaire was prepared with 19 questions with direct answers, so that the results could be analyzed and described the results and conclusions of the study. 


\section{Results}

When examining the results of the survey it was found that $56 \%$ of employees surveyed found themselves motivated and satisfied in the organization where they work and see it in a positive way. The other $44 \%$ had some degree of dissatisfaction and frustration in the performance of their work activities.

Of the 15 interviewed, such answers were obtained:

- 07 are dissatisfied with the work of the human resources department;

- 07 consider their sector disorganized;

- 05 responded that their performance is not evaluated;

- 12 state that they do not have growth possibility;

- 15 said that the company does not provide training;

- 15 said that motivational methods are not applied;

- 15 do not receive feedback from their superior;

- 15 state that there is no material for training;

- 11 do not try to reach their limits on their activities;

- 11 do not accept to take new responsibilities;

In contrast:

- 13 know the company work philosophy;

- 10 have their development evaluated;

- 15 affirm that their opinions are considered by their superior;

- 15 affirm that the company recognizes their efforts;

- 15 feel responsible by the position they have;

- 14 feel pride by their work;

The results show that most employees remain motivated and willing to develop their tasks, however, it lacks larger investments by the company in the area of human enhancement, as it can be seen most emphatically by the responses to questions about training and development, motivation and feedback. In answers to questions about the recognition, pride, commitment, it is understood that workers strive, but up to date of the questionnaire they received no encouragement from the company, according to the most emphatic points of the survey.

The questions were related to the attitudes of managers towards their employees; it refers to material and environmental conditions for the development of their activities, in addition to the recognition and appreciation of their efforts and incentives, such as investment in training and participation as part of the company.

\section{Conclusions}

The construction of this research was conducted in order to understand the facts related to the ability of the relationship between "employees and employers", leaders and followers, employees and managers and analyze this field of knowledge with regard to organizational management.

This study reveals how important, necessary effective motivation of teams and work groups is and recognizes how the role of people and their relationships in organizations are for the success and achievement of corporate goals, considering the good performance of the leader.

At present, it is notoriously known that the company generates profits, because a happy employee produces more and better. This new context is known to the world of work, but it is still easy to find 
organizations that have not paid attention to the importance of valuing "people" in labor relations.

On the contrary, there are companies that take this ability to good relationships very seriously and improve themselves increasingly focusing on solving problems regardless of the resources that the company can offer to encourage and satisfy employees through collective participation towards a common good.

However, the considerations of this study, from the responses to the survey, show the total lack of investment or interest in training employees of the company studied, which probably negatively influenced the acceptance of new tasks and test limits by employees as a result of reluctance to accept new challenges without proper training and with the requirement to reach results.

In contrast, employees are aware about the company's philosophy, are heard by the head and take pride in their work, which suggests that the environment is comfortable and perhaps even somewhat familiar, in this way, the roles are well defined and fixed, there is no provision or expansion project, and when there is an opportunity, it will probably be granted to the most reliable, due to long years of cohabitation.

Because it is a small company and the highest administrative posts are occupied by the family who owns the business, the motivational work could start for a career plan, which would establish themselves in specific positions according to the tasks performed, but there should be created position according to the responsibilities required for such tasks that benefit the commitment shown by the employees, which would imply a salary increase.

For initially fulfilling the need of basic training to the implementation of specific training and training courses, accessible and easy to read guidelines would be necessary where positions would be described, in addition to specific training.

Finally, the professional attitude of the manager, coupled with the incentives that the company can offer, such as training, reward and recognition for effort, for example, they provide a work clime drawn to productivity increase, the motivation of the employee as the results obtained in the investigation, that enabled a better understanding of this delicate relationship between companies and employees inserted in a new competitive environment that involves employees and employers.

\section{References}

Arnold, K. A., Barling, J., \& Kelloway, E. K. (2001). Transformational leadership or the iron cage: Which predicts trust, commitment and team efficacy?. Leadership \& Organization Development Journal, 22, 315-320.

Bennis, W. (1996). Creating a leader. São Paulo: Atlas.

Castro, A. P. de. (1996). Self-motivation: How to create such energy and share with people. Rio de Janeiro: Campus.

Chiavenato, I. (2009). Managing people: A decisive step to a participative administration. São Paulo: Makron Books.

Chiavenato, I. (2010). Managing people: The new role of human resources in organizations. Rio de Janeiro: Campos.

D'Auria, A. (2007). Motivation. Managing and Business, 9(37), 1-5.

Dejours, C. (1996). A new view on human suffering in organizations. In C. Jean-François (Ed.), The individual within organizations. São Paulo: Atlas.

França, L. S. (2011). Difference between team and work force. Retrieved from http://www.guiarh.com.br

Hunter, J. C. (2007). The servant. São Paulo: Sextante.

Juchem, D. M., \& Cespedes, E. A. H. (2012). The importance of communication and interpersonal relations in Agribusiness enterprises. Chinese Business Review, 11(10), 923-930.

Kardec, A. (2002). Strategic management and performance evaluation. Rio de Janeiro: Quality Mark Abraman.

Kaspary, M. C., \& Seminotti, N. A. (2012). Group processes and team management in the contemporary work: Comprehension through the complex thought. Retrieved from http://www.scielo.br/scielo.php?script=sci_arttext\&pid=S1678-69712012000200002\&lng=pt\&nrm=iso 
Lacombe, B. M. B., \& Albuquerque, L. G. (2008). Evaluation and measurement outcomes in people management: A study of the major companies operating in Brazil. Revista de Administração, 43(1), 5-16.

Oliveira, P. M., \& Limongi-França, A. C. (2005). Management assessment of quality of work life programs. Revista de Administração de Empresaselectron, 4(1), 11-16.

Peters, T. J. (1989). Leadership: Positive and negative facts. São Paulo: Nova Cultural.

Reis, A. M. V. (2007). Team development. Rio de Janeiro: FGV.

Sacomano Neto, M., \& Escrivão Filho, E. (2000). Organizational structure and work teams: A study of organizational change in four major industrial companies. Retrieved from http://dx.doi.org/10.1590/S0104-530X2000000200004

Silva, A. R., Junquinho, G. S., \& Carrieri, A. P. (2008). Human resources policies: Instruments and consensus of ambiguity. Retrieved from http://www.scielo.br/pdf/rac/ 12n1/a02v12n1.pdf

Stettner, M. (2006). Guidelines of the new manager. Rio de Janeiro: Sextante.

Stevens, M. (2001). Extreme management. Rio de Janeiro: Campus.

Tanure, B., Evans, P., \& Cancado, V. L. (2010). The four faces of human resources: Analyzing the performance of human resources management in enterprises in Brazil. Retrieved from http://dx.doi.org/10.1590/S1415-65552010000400003

Tracey, B. J., \& Hinkin, T. R. (1998). Transformational leadership or effective managerial practices. Group \& Organization Management, 23, 220-236.

Vergara, S. C. (2006). People management (5th ed.). São Paulo: Atlas.

Wagner III, J. A., \& Hollenbeck, J. R. (2003). Organizational behavior. São Paulo: Saraiva. 